\title{
Evaluasi Manajemen Perawatan dengan Metode Reliability Centered Maintenance (RCM) II pada Mesin Cane Cutter 1 dan 2 di Stasiun Gilingan PG Meritjan - Kediri
}

\author{
Cahyo Purnomo Prasetyo \\ Universitas Kahuripan Kediri \\ cahyo_pp_04@yahoo.com
}

\begin{abstract}
ABSTRAK
Penelitian ini bertujuan untuk menentukan kebijakan perawatan optimal yang dapat mengurangi biaya perbaikan (repair cost) dan biaya konsekwensi operasional (operational consequence cost). Metode yang diterapkan pada penelitian ini adalah Reliability Centered Maintenance (RCM) II. Penelitian ini difokuskan pada mesin Cane Cutter 1 dan 2 dengan pertimbangan beberapa aspek yaitu : pengaruh kegagalan terhadap pencapaian target produksi, resiko keselamatan kerja dan biaya perawatan yang akan ditimbulkan. Dari hasil penelitian dapat diketahui bahwa komponen kritis pada mesin Cane Cutter 1 dan 2 adalah : Pisau dan Baut Pisau. Perawatan yang dilakukan untuk mengantisipasi dan mengatasi kegagalan yang terjadi pada komponen mesin tersebut adalah proactive task yang meliputi : scheduled restoration task dan scheduled discard task. Rata-rata penurunan biaya perawatan total yang didapatkan dengan mengurangkan 'biaya total pada interval perawatan awal' dan 'biaya total pada interval perawatan optimal' adalah 14,82 \%.
\end{abstract}

Kata Kunci: cane cutter, downtime, pabrik gula.

\begin{abstract}
This research aims to determine the optimal maintenance policy which could reduce repair cost and operational consequence cost. The methods which applied in this research is Reliability Centered Maintenance (RCM) II. This research focuses on Cane Cutter 1 and 2 machines by considering several aspects, such as and effect of any failure on production target achievement, work safety risk and maintenance cost which might be caused by the critical condition. The result showed that some critical components at the Cane Cutter 1 and 2 machines were : Blade and Blade Bolt. The maintenance which could be done to anticipate and deal with any failure occurring in the machine components was called proactive task comprising : scheduled restoration task and scheduled discard task. The average reduction in total maintenance costs which was obtained by subtracting 'total costs at initial maintenance interval' and 'total costs at optimal maintenance interval' amounted to $14,82 \%$.
\end{abstract}

Keywords: cane cutter, downtime, sugar factory 


\section{PENDAHULUAN}

Dalam era persaingan global seperti saat ini, perusahaan dituntut untuk meningkatkan produktivitas dalam perusahaannya agar tetap bersaing dengan perusahaan lainnya. Khusus pada perusahaan di bidang manufaktur, peningkatan produktivitas pada sistem produksi merupakan hal mutlak yang harus dilakukan. Salah satu indikator dalam peningkatan produktivitas tersebut adalah tingkat reliabilitas dari mesin-mesin produksi pada perusahaan. Dalam mengukur seberapa baik reliabilitas suatu mesin produksi maka diperlukan proses pemeliharaan (maintenance) yang efektif dan efisien bagi perusahaan.

PG Meritjan sebagai bagian industri gula Indonesia memiliki tanggung jawab besar terutama untuk memenuhi kebutuhan gula nasional. Untuk mendukung perannya yang sangat kritis, maka inefisiensi pabrik gula akibat dari kondisi mesin produksi yang aus harus segera diatasi. Dan keberadaan sistem perawatan mesin produksi pabrik gula yang baik adalah sangat penting. Karena kerusakan mesin yang dapat terjadi sewaktu-waktu tidak hanya akan dapat menyebabkan berhentinya proses produksi, namun juga mengancam keselamatan kerja karyawan. Dan hal ini sangat merugikan perusahaan, karena selain perusahaan akan tetap mengeluarkan cost untuk membayar tenaga kerja reguler tanpa menghasilkan produk, kecelakaan kerja akibat kerusakan dapat menurunkan moral karyawan.

Salah satu mesin produksi PG Meritjan adalah mesin Cane Cutter 1 dan 2 yang berada di Stasiun Gilingan. Mesin Cane Cutter 1 dan 2 berfungsi untuk mencacah/memotong tebu utuk memaksimalkan proses pemerahan tebu. Berdasarkan hasil observasi yang telah didapatkan maka diperlukan perencanaan kebijakan perawatan yang optimal dengan metode Reliability Centered Maintenance (RCM) II. RCM II sendiri adalah metode terintegrasi analisis kuantitatif dan kualitatif pada penentuan perencanaan perawatan mesin dimana RCM II memiliki keuntungan dalam penentuan rencana perawatan yang difokuskan pada mesin-mesin kritis serta menghindari aktivitas perawatan yang tidak diperlukan.

Tujuan diadakannya

penelitian ini adalah untuk menetapkan aktivitas perawatan sesuai RCM II Decision Worksheet dan menghitung Penurunan Biaya Perawatan secara keseluruhan.

Agar penulisan dapat berjalan dengan baik dan sesuai dengan alurnya maka perlu diberikan batasan-batasan masalah sebagai berikut :

1. Obyek penelitian ini hanya dibatasi pada mesin Cane Cutter 1 dan 2 dan komponen kritis : Pisau dan Baut Pisau.

2. Penyelesaian masalah dibatasi sampai pada menetapkan aktivitas perawatan sesuai RCM II Decision Worksheet dan menghitung Penurunan Biaya Perawatan secara keseluruhan.

\section{Perawatan (Maintenance)}

Melewati lebih dari 20 tahun, perawatan telah berubah, mungkin melebihi ilmu manajemen yang lain. Perubahan berasal dari peningkatan besar dalam jumlah dan macam dari aset fisik (pabrik, peralatan dan bangunan) yang harus dikelola, lebih banyak rancangan kompleks, teknik perawatan baru dan perubahan 
pandangan pada organisasi perawatan serta tanggungjawab.

Perawatan juga dipengaruhi oleh perubahan ekspektasi. Hal ini termasuk peningkatan cepat kesadaran bahwa kegagalan peralatan mempengaruhi keselamatan dan lingkungan, peningkatan kesadaran dari hubungan antara perawatan dan kualitas produk, dan peningkatan tekanan untuk mencapai high plant availability dan untuk menekan biaya.

Perawatan (maintenance) merupakan suatu aktifitas yang dilakukan agar peralatan atau item dapat dijalankan sesuai standard performansi semula. Perawatan (maintenance) sebagai suatu tindakan yang dibutuhkan untuk mencapai suatu hasil yang dapat mengembalikan item atau mempertahankan item pada kondisi yang selalu dapat berfungsi. Perawatan sebagai salah satu kegiatan pendukung yang bertujuan untuk menjamin kelangsungan fungsional suatu sistem produksi (peralatan, mesin dan fasilitas lainnya), sehingga pada saat dibutuhkan dapat dipakai sesuai dengan kondisi yang diharapkan. Kondisi di atas dapat dicapai antara lain dengan melakukan perencanaan penjadwalan tindakan perawatan dengan tetap memperhatikan fungsi pendukungnya dengan kriteria minimasi biaya. Tujuan utama dari dilakukannya sistem manajemen perawatan adalah sebagai berikut :

1. Memperpanjang usia pakai fasilitas produksi.

2. Menjamin tingkat ketersediaan yang optimum dari fasilitas produksi.

3. Menjamin kesiapan operasional seluruh fasilitas yang diperlukan untuk pemakaian darurat.
4. Menjamin keselamatan operator dan pemakai fasilitas.

\section{Reliability Centered Maintenance II (RCM II)}

Reliability

Centered

Maintenance (RCM) pada dasarnya menggabungkan beberapa teknik manajemen resiko dan alat yang sudah diketahui secara baik, seperti Failure Mode dan Effect Analysis (FMEA) dan decision tree, dalam sebuah pendekatan sistematis untuk mendukung keputusan perawatan yang efektif dan efisien.

Reliability

Centered Maintenance (RCM) adalah proses yang digunakan untuk menentukan pendekatan paling efektif pada perawatan. RCM menggunakan tindakan identifikasi yang bila dilakukan akan mengurangi kemungkinan dari kegagalan dan dimana paling efektif biaya. Strategi perawatan ini tidak diaplikasikan secara independen, namun terintegrasi untuk mencapai manfaat dari kekuatan respektifnya untuk mengoptimasi fasilitas dan kemampuan operasi peralatan serta efisiensi saat menurunkan biaya life cycle.

Reliability

Centered Maintenance adalah sebuah proses yang digunakan untuk menentukan apa yang harus dilakukan untuk memastikan bahwa semua aset fisik terus melakukan apa yang user ingin dilakukan dalam kondisi operasinya saat ini. RCM berdasar pada paham bahwa setiap aset digunakan untuk memenuhi fungsi atau fungsi spesifik, dan perawatan itu berarti melakukan apapun yang perlu untuk memastikan bahwa aset terus memenuhi fungsinya untuk kepuasan user. 


\section{Konsep Keandalan}

Salah satu aspek yang dapat mempengaruhi keberhasilan suatu produk adalah keandalan komponen, sub sistem, atau sistem tersebut untuk tidak mengalami kegagalan dalam jangka waktu tertentu. Penerapan teori keandalan dapat membantu untuk memperkirakan peluang suatu komponen, sub sistem, atau sistem untuk dapat bekerja sesuai dengan tujuan yang diinginkan dalam kurun waktu tertentu.

Keandalan ini menjadi sangat penting karena akan mempengaruhi biaya pemeliharaan yang pada akhirnya akan berpengaruh pula terhadap keberhasilan suatu produk.

\section{METODE PENELITIAN}

Tahapan penelitian menunjukkan langkah-langkah yang dilakukan dalam penelitian. Tahapan penelitian dapat dilihat pada gambar 1.

Gambar 1 merupakan alur penelitian yang dilakukan. Penelitian dimulai dengan Tahap Identifikasi Permasalahan (Perumusan Masalah dan Penentuan Tujuan, Studi Pustaka, Studi Pendahuluan dan Penentuan Komponen Kritis Mesin), Tahap Pengumpulan Data, Tahap Pengolahan Data (System Function \& Function Failure, Failure Mode \& Effect Analysis, Failure Consequence, Proactive Task \& Default Action, Proposed Task, Penentuan Distribusi Waktu Antar Kerusakan/Perbaikan, Penentuan Interval Perawatan, Penentuan Biaya Perawatan Berdasarkan Interval Perawatan Optimal), Tahap Analisis dan Interpretasi, lalu membuat Kesimpulan dan Saran
Untuk mendukung penelitian ini, maka digunakan beberapa data kualitatif dan kuantitatif.

Adapun data-data kualitatif tersebut meliputi :

1. Data fungsi mesin.

2. Data kegagalan.

3. Data penyebab kegagalan.

4. Data efek yang ditimbulkan apabila kegagalan tersebut terjadi.

Sedangkan data-data kuantitatif meliputi :

1. Data waktu antar kerusakan mesin (time to failure) dan data waktu antar perbaikan (time to repair).

2. Data biaya kegagalan mesin yang meliputi data biaya operasional, biaya tenaga kerja, biaya penggantian komponen serta biaya perawatan mesin.

\section{HASIL DAN PEMBAHASAN \\ Pemilihan Mesin Kritis}

Di Stasiun Gilingan PG

Meritjan terdapat 2 set mesin Cane Cutter. Pada penelitian ini semua komponen pada mesin Cane Cutter 1 dan 2 dimasukkan sebagai komponen kritis

\section{FMEA (Failure Mode and Effect Analysis)}

FMEA berfungsi untuk menganalisis sistem peralatan berdasarkan fungsi sub sistem yang dalam hal ini komponen atau unit, dan bagaimana komponen tersebut gagal dalam mencapai standart performansinya.

Penyusunan tabel FMEA dilakukan berdasarkan data fungsi komponen dan laporan perawatan yang kemudian dapat ditentukan berbagai penyebab kegagalan (failure mode) yang mengakibatkan kegagalan fungsi (functional failures). Selain itu berdasarkan informasi dari operator dan masinis Stasiun 


Gilingan dapat diketahui seberapa
besar pengaruh failure mode
terhadap performansi mesin dan

kualitas produk yang dihasilkan. Tabel 1 dan Tabel 2 adalah tabel FMEA mesin Cane Cutter 1 dan 2 :

Tabel 1. RCM II Information Worksheet Mesin Cane Cutter 1

\begin{tabular}{|c|c|c|c|c|c|c|c|c|}
\hline No & Komponen & & ction & & ctional Failures & & ure Mode & Failure Effect \\
\hline 1 & Pisau & 1 & $\begin{array}{l}\text { Memotong/menc } \\
\text { acah tebu } \\
\text { hingga } \\
\text { memenuhi } \\
\text { Preparation } \\
\text { Index } \\
(\mathrm{PI})>80 \%\end{array}$ & A & $\begin{array}{l}\text { Tidak mampu } \\
\text { memotong/menc } \\
\text { acah tebu dan } \\
\text { memenuhi } \\
\mathrm{PI}>80 \%\end{array}$ & 2 & $\begin{array}{l}\text { Pisau tunpul } \\
\text { akibat korosi } \\
\text { Pisau lepas } \\
\text { karena } \\
\text { pemasangan } \\
\text { baut pisau } \\
\text { kurang kencang } \\
\text { Pisau patah } \\
\text { karena kelelahan } \\
\text { pada bahan } \\
\text { (fatigue) }\end{array}$ & $\begin{array}{l}\text { Proses } \\
\text { pemotongan/pencacahan tebu } \\
\text { kurang optimal. } \\
\text { Proses pemotongan/ } \\
\text { pencacahan tebu berhenti } \\
\text { untuk melakukan penggantian } \\
\text { pisau baru. } \\
\text { Potongan pisau yang terlontar } \\
\text { dapat membahayakan } \\
\text { keselamatan operator dan } \\
\text { pekerja lainnya. } \\
\text { Proses } \\
\text { pemotongan/pencacahan tebu } \\
\text { berhenti untuk melakukan } \\
\text { penggantian pisau baru. } \\
\text { Potongan pisau yang terlontar } \\
\text { dapat membahayakan } \\
\text { keselamatan operator dan } \\
\text { pekerja lainnya. }\end{array}$ \\
\hline 2 & Baut pisau & 1 & $\begin{array}{l}\text { Menyatukan } \\
\text { pisau pada } \\
\text { piringan baja }\end{array}$ & A & $\begin{array}{l}\text { Tidak mampu } \\
\text { menyatukan } \\
\text { pisau pada } \\
\text { piringan baja }\end{array}$ & 1 & $\begin{array}{l}\text { Baut pisau lepas } \\
\text { karena } \\
\text { pemasangan } \\
\text { kurang kencang. } \\
\text { Baut pisau } \\
\text { longgar, lepas } \\
\text { ataupun putus } \\
\text { karena kelelahan } \\
\text { pada bahan } \\
\text { (fatigue) }\end{array}$ & $\begin{array}{l}\text { Pisau terlepas dari piringan } \\
\text { baja. } \\
\text { Potongan pisau yang terlontar } \\
\text { dapat membahayakan } \\
\text { keselamatan operator dan } \\
\text { pekerja lainnya } \\
\text { Pisau goyang dan terlepas } \\
\text { dari piringan baja. } \\
\text { Potongan pisau yang terlontar } \\
\text { dapat membahayakan } \\
\text { keselamatan operator dan } \\
\text { pekerja lainnya }\end{array}$ \\
\hline
\end{tabular}

Tabel 2. RCM II Information Worksheet Mesin Cane Cutter 2

\begin{tabular}{|c|c|c|c|c|c|c|c|c|}
\hline No & Komponen & & Function & & ctional Failures & & Failure Mode & $\begin{array}{l}\text { Failure Effect } \\
\end{array}$ \\
\hline 1 & Pisau & 1 & $\begin{array}{l}\text { Memotong/menc } \\
\text { acah tebu } \\
\text { hingga } \\
\text { memenuhi } \\
\text { Preparation } \\
\text { Index } \\
(\mathrm{PI})>80 \%\end{array}$ & A & $\begin{array}{l}\text { Tidak mampu } \\
\text { memotong/menc } \\
\text { acah tebu dan } \\
\text { memenuhi } \\
\mathrm{PI}>80 \%\end{array}$ & 2 & $\begin{array}{l}\text { Pisau tunpul } \\
\text { akibat korosi } \\
\text { Pisau lepas } \\
\text { karena } \\
\text { pemasangan } \\
\text { baut pisau } \\
\text { kurang kencang } \\
\text { Pisau patah } \\
\text { karena kelelahan } \\
\text { pada bahan } \\
\text { (fatigue) }\end{array}$ & $\begin{array}{l}\text { Proses pemotongan/pencacahan } \\
\text { tebu kurang optimal. } \\
\text { Proses pemotongan/ pencacahan } \\
\text { tebu berhenti untuk melakukan } \\
\text { penggantian pisau baru. } \\
\text { Potongan pisau yang terlontar } \\
\text { dapat membahayakan } \\
\text { keselamatan operator dan } \\
\text { pekerja lainnya. } \\
\text { Proses pemotongan/ pencacahan } \\
\text { tebu berhenti untuk melakukan } \\
\text { penggantian pisau baru. } \\
\text { Potongan pisau yang terlontar } \\
\text { dapat membahayakan } \\
\text { keselamatan operator dan } \\
\text { pekerja lainnya. }\end{array}$ \\
\hline
\end{tabular}




\begin{tabular}{|c|c|c|c|c|c|c|c|c|}
\hline No & Komponen & & Function & & nctional Failures & & Failure Mode & Failure Effect \\
\hline 2 & Baut pisau & 1 & $\begin{array}{l}\text { Menyatukan } \\
\text { pisau pada } \\
\text { piringan baja }\end{array}$ & $\mathrm{A}$ & $\begin{array}{l}\text { Tidak mampu } \\
\text { menyatukan } \\
\text { pisau pada } \\
\text { piringan baja }\end{array}$ & 1 & $\begin{array}{l}\text { Baut pisau lepas } \\
\text { karena } \\
\text { pemasangan } \\
\text { kurang kencang. } \\
\text { Baut pisau } \\
\text { longgar, lepas } \\
\text { ataupun putus } \\
\text { karena kelelahan } \\
\text { pada bahan } \\
\text { (fatigue) }\end{array}$ & $\begin{array}{l}\text { Pisau terlepas dari piringan baja. } \\
\text { Potongan pisau yang terlontar } \\
\text { dapat membahayakan } \\
\text { keselamatan operator dan } \\
\text { pekerja lainnya } \\
\text { Pisau goyang dan terlepas dari } \\
\text { piringan baja. } \\
\text { Potongan pisau yang terlontar } \\
\text { dapat membahayakan } \\
\text { keselamatan operator dan } \\
\text { pekerja lainnya }\end{array}$ \\
\hline
\end{tabular}

Tabel 3. RCM II Decision Worksheet Mesin Cane Cutter 1

\begin{tabular}{|c|c|c|c|c|c|c|c|c|c|c|c|c|c|c|c|}
\hline \multirow[t]{2}{*}{ no } & \multirow[t]{2}{*}{ Komponen } & \multicolumn{3}{|c|}{$\begin{array}{c}\text { Information } \\
\text { reference }\end{array}$} & \multicolumn{4}{|c|}{ Consequence evalution } & \multirow{2}{*}{$\begin{array}{l}\text { H1 } \\
\text { S1 } \\
\text { O1 } \\
\text { N1 }\end{array}$} & \multirow{2}{*}{$\begin{array}{l}\mathrm{H} 2 \\
\mathrm{~S} 2 \\
\mathrm{O} 2 \\
\mathrm{~N} 2\end{array}$} & \multirow{2}{*}{$\begin{array}{l}\text { H3 } \\
\text { S3 } \\
\text { O3 } \\
\text { N3 }\end{array}$} & \multicolumn{3}{|c|}{ Default action } & \multirow{2}{*}{ PROPOSED TASK } \\
\hline & & $\mathbf{F}$ & FF & FM & $\mathbf{H}$ & $\mathbf{S}$ & $E$ & 0 & & & & H4 & H5 & S4 & \\
\hline \multirow{3}{*}{1} & \multirow{3}{*}{ Pisau } & \multirow{3}{*}{1} & \multirow{3}{*}{$A$} & 1 & $\mathrm{Y}$ & $\mathrm{N}$ & $\mathrm{N}$ & $\mathrm{Y}$ & $\mathrm{N}$ & $\mathrm{Y}$ & & & & & Scheduled restoration task \\
\hline & & & & 2 & Y & Y & & & $\mathrm{N}$ & Y & & & & & Scheduled restoration task \\
\hline & & & & 3 & Y & Y & & & $\mathrm{N}$ & $\mathrm{N}$ & $\mathrm{Y}$ & & & & Scheduled discard task \\
\hline \multirow{2}{*}{2} & \multirow{2}{*}{ Baut Pisau } & \multirow{2}{*}{1} & \multirow{2}{*}{$A$} & 1 & $\mathrm{Y}$ & $\mathrm{Y}$ & & & $\mathrm{N}$ & $\mathrm{Y}$ & & & & & Scheduled restoration task \\
\hline & & & & 2 & $\mathrm{Y}$ & $\mathrm{Y}$ & & & $\mathrm{N}$ & $\mathrm{N}$ & $\mathrm{Y}$ & & & & Scheduled discard task \\
\hline
\end{tabular}

Tabel 4. RCM II Decision Worksheet Mesin Cane Cutter 2

\begin{tabular}{|c|c|c|c|c|c|c|c|c|c|c|c|c|c|c|c|}
\hline \multirow[t]{2}{*}{ ] } & \multirow[t]{2}{*}{ Komponen } & \multicolumn{3}{|c|}{$\begin{array}{c}\text { Information } \\
\text { reference }\end{array}$} & \multicolumn{4}{|c|}{$\begin{array}{c}\text { Consequence } \\
\text { evalution }\end{array}$} & \multirow{2}{*}{$\begin{array}{l}\mathrm{H} 1 \\
\text { S1 } \\
\text { O1 } \\
\text { N1 }\end{array}$} & \multirow{2}{*}{$\begin{array}{l}\mathrm{H} 2 \\
\mathrm{~S} 2 \\
\mathrm{O} 2 \\
\mathrm{~N} 2\end{array}$} & \multirow{2}{*}{$\begin{array}{l}\text { H3 } \\
\text { S3 } \\
\text { O3 } \\
\text { N3 }\end{array}$} & \multicolumn{3}{|c|}{ Default action } & \multirow{2}{*}{ PROPOSED TASK } \\
\hline & & $\mathbf{F}$ & FF & FM & $\mathbf{H}$ & $\mathbf{S}$ & $\mathbf{E}$ & 0 & & & & H4 & H5 & S4 & \\
\hline \multirow{3}{*}{1} & \multirow{3}{*}{ Pisau } & \multirow{3}{*}{1} & \multirow{3}{*}{$A$} & 1 & $\mathrm{Y}$ & $\mathrm{N}$ & $\mathrm{N}$ & $\mathrm{Y}$ & $\mathrm{N}$ & $\mathrm{Y}$ & & & & & Scheduled restoration task \\
\hline & & & & 2 & $\mathrm{Y}$ & $\mathrm{Y}$ & & & $\mathrm{N}$ & $\mathrm{Y}$ & & & & & Scheduled restoration task \\
\hline & & & & 3 & Y & $\mathrm{Y}$ & & & $\mathrm{N}$ & $\mathrm{N}$ & $\mathrm{Y}$ & & & & Scheduled discard task \\
\hline \multirow{2}{*}{2} & \multirow{2}{*}{ Baut Pisau } & \multirow{2}{*}{1} & \multirow{2}{*}{$A$} & 1 & $\mathrm{Y}$ & $\mathrm{Y}$ & & & $\mathrm{N}$ & Y & & & & & Scheduled restoration task \\
\hline & & & & 2 & $\mathrm{Y}$ & $\mathrm{Y}$ & & & $\mathrm{N}$ & $\mathrm{N}$ & $\mathrm{Y}$ & & & & Scheduled discard task \\
\hline
\end{tabular}

Tabel 5. Hasil Uji Distribusi Mesin Cane Cutter 1 dan 2

\begin{tabular}{|c|c|c|c|c|c|c|c|c|c|}
\hline \multirow[b]{2}{*}{$\begin{array}{l}\text { Sub System } \\
\text { (mesin) }\end{array}$} & \multirow{2}{*}{\multicolumn{2}{|c|}{ Komponen }} & \multirow[b]{2}{*}{ Distribusi } & \multicolumn{6}{|c|}{ Parameter } \\
\hline & & & & $\alpha$ & $\boldsymbol{\beta}$ & $\mathbf{Y}$ & $\lambda$ & $\mu$ & $\boldsymbol{\sigma}$ \\
\hline \multirow{4}{*}{ Cane Cutter 1} & & $\mathrm{Tf}$ & Weibull 3 & 1.8023 & 140.0439 & 82.35 & & & \\
\hline & Pisau & $\mathrm{Tr}$ & Weibull 2 & 1.6906 & 3.1386 & & & & \\
\hline & Baut & Tf & Weibull 3 & 1.8922 & 154.1126 & 124.0658 & & & \\
\hline & pisau & $\operatorname{Tr}$ & Eksponential 2 & & & 0.2957 & 0.2948 & & \\
\hline \multirow{4}{*}{ Cane Cutter 2} & Pisau & $\mathrm{Tf}$ & Weibull 2 & 2.0451 & 136.8265 & & & & \\
\hline & risau & $\operatorname{Tr}$ & Normal & & & & & 3.1867 & 2.1389 \\
\hline & Baut & Tf & Weibull 3 & 1.1343 & 155.9964 & 121.4781 & & & \\
\hline & pisau & $\mathrm{Tr}$ & Weibull 3 & 1.1325 & 3.4655 & -0.0511 & & $1.1883^{-}$ & 1.1005 \\
\hline
\end{tabular}

\section{Decision Worksheet}

RCM II Decision Worksheet digunakan untuk mencari jenis kegiatan perawatan (maintenance task) yang tepat dan memiliki kemungkinan untuk dapat mengatasi setiap failure mode. Berikut ini adalah tabel 3 dan tabel 4 :

\section{Penentuan Distribusi}

Pengujian distribusi dilakukan terhadap data waktu antar kerusakan (Tf) dan waktu perbaikan (Tr). Pengujian distribusi terhadap waktu antar kerusakan digunakan untuk mendapatkan nilai kemungkinan terjadinya kerusakan pada waktu 
tertentu, kemungkinan mesin dapat beroperasi sampai waktu tertentu (fungsi keandalan) dan untuk menghitung ekspektasi siklus perbaikan yang akan digunakan untuk mendapatkan nilai dari biaya akibat adanya kerusakan.

Hasil pengujian distribusi dengan software Reliasoft Weibull ++4 pada mesin Cane Cutter 1 dan 2 dapat dilihat pada tabel 5 .

Perhitungan Interval Perawatan Optimal dan Penurunan Biaya Perawatan

Langkah yang diambil setelah dilakukan uji distribusi terhadap waktu antar kerusakan (Tf) dan waktu perbaikan (Tr) adalah menentukan interval perawatan (TM) berdasarkan minimasi biaya.

Biaya yang berhubungan dengan perawatan

1. Biaya Tenaga Kerja (CW)

2. Biaya Perawatan (CM)

3. Biaya Konsekwensi Operasional (CO)

4. Biaya Perbaikan (CR)

Dimana :

$\mathrm{CV}=$ Biaya Tenaga Kerja $(\mathrm{CW})+$ Biaya Konsekwensi Operasional (CO)

Sehingga besar Biaya Perbaikan (CR) dapat dihitung sebagai berikut :

$\mathrm{CR}=$ Biaya Penggantian Komponen $(\mathrm{CF})+(\mathrm{CV} \times \mathrm{MTTR})$

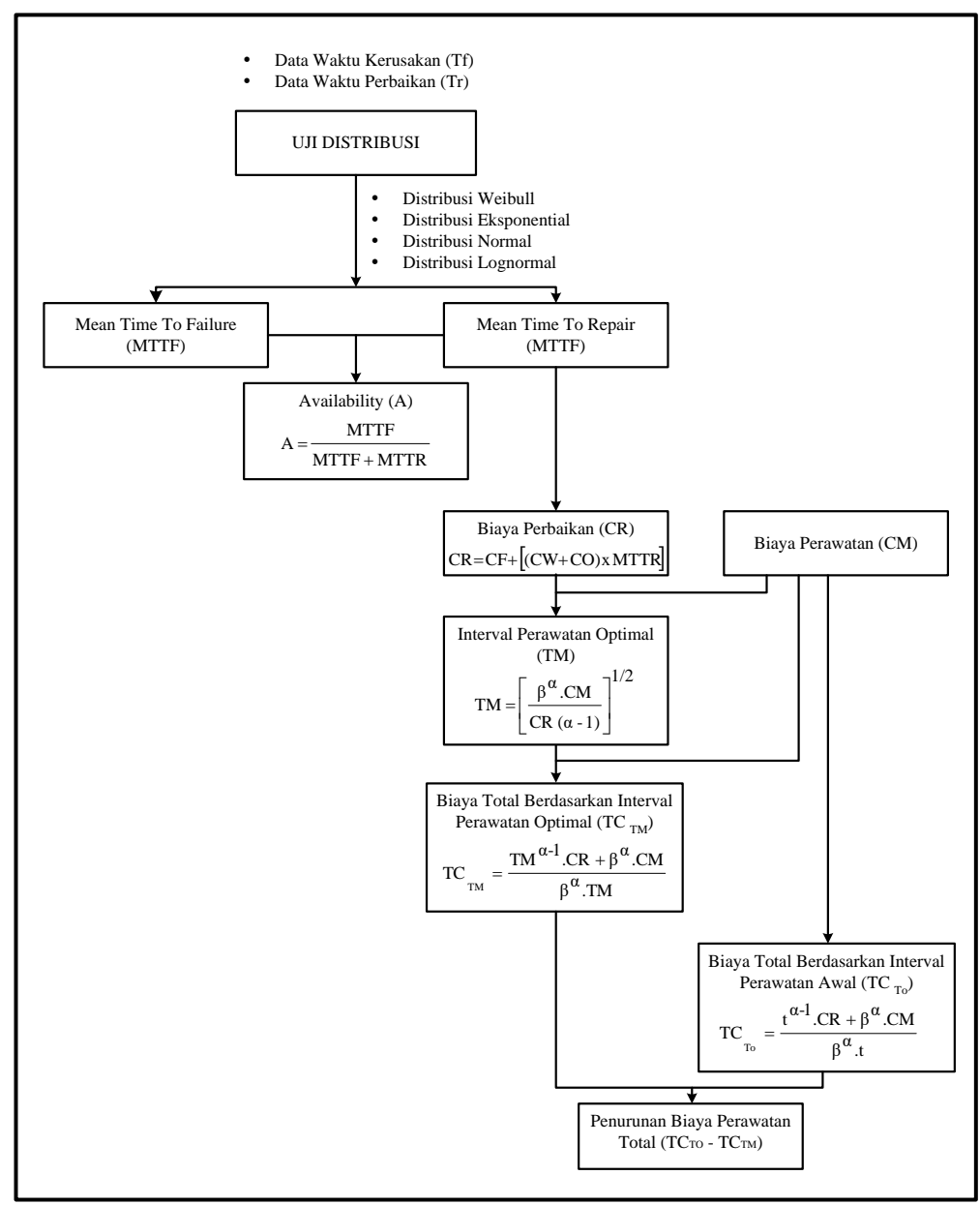

Gambar 1. Skema Tahap Perhitungan 
$\mathrm{CR}=$ Biaya Penggantian Komponen $(\mathrm{CF})+[(\mathrm{CW}+\mathrm{CO}) \times \mathrm{MTTR}]$

\section{Perhitungan interval perawatan (TM) dan biaya perawatan komponen (TC)}

Setelah dilakukan pengujian distribusi perhitungan biaya (tenaga kerja, perawatan, konsekwensi operasional, perbaikan), maka akan dilanjutkan ke langkah berikutnya yaitu menghitung MTTF (waktu ratarata antar kerusakan), MTTR (waktu rata-rata antar perbaikan), TM (interval perawatan optimal) dan TC (biaya perbaikan dan perawatan berdasarkan interval perawatan optimal).

Untuk mempermudah pemahaman, maka tahap-tahap perhitungan dapat dilihat pada gambar 1.

Perhitungan Interval perawatan (TM) dan Penurunan Biaya Perawatan dengan Software Mathcad 12 dapat dilihat pada tabel 6:

Tabel 6. Perhitungan Interval perawatan Optimal Mesin Cane Cutter 1 dan 2

\begin{tabular}{|c|c|c|c|c|c|c|c|c|c|c|}
\hline No & $\begin{array}{c}\text { Sub } \\
\text { Sistem }\end{array}$ & Komponen & $\begin{array}{l}\text { MTTF } \\
\text { (jam) }\end{array}$ & $\begin{array}{l}\text { MTTR } \\
\text { (jam) }\end{array}$ & A & $\begin{array}{c}\text { CF } \\
\text { (Rp) }\end{array}$ & $\begin{array}{c}\text { CV } \\
\text { (Rp) }\end{array}$ & $\begin{array}{c}\text { CR } \\
\text { (Rp) }\end{array}$ & $\begin{array}{c}\text { CM } \\
\text { (Rp) }\end{array}$ & $\begin{array}{c}\mathrm{TM} \\
\text { (jam) }\end{array}$ \\
\hline \multirow{2}{*}{1} & Cane & Pisau & 197 & 1.513 & 0.992378333 & $500,000.00$ & $23,430,166.67$ & $35,949,842.17$ & $10,217.85$ & 1.705 \\
\hline & Cutter 1 & Baut Pisau & 186 & 2.741 & 0.973083261 & $24,750.00$ & $23,430,166.67$ & $64,246,836.84$ & $10,217.85$ & 1.609 \\
\hline \multirow{2}{*}{2} & Cane & Pisau & 150 & 3.1867 & 0.97919728 & $500,000.00$ & $23,430,166.67$ & $75,164,912.13$ & $10,217.85$ & 1.722 \\
\hline & Cutter 2 & Baut Pisau & 180 & 4.018 & 0.978165179 & $24,750.00$ & $23,430,166.67$ & $94,167,159.68$ & $10,217.85$ & 1.25 \\
\hline
\end{tabular}

Tabel 7. Penurunan Biaya Perawatan Mesin Cane Cutter 1 dan 2

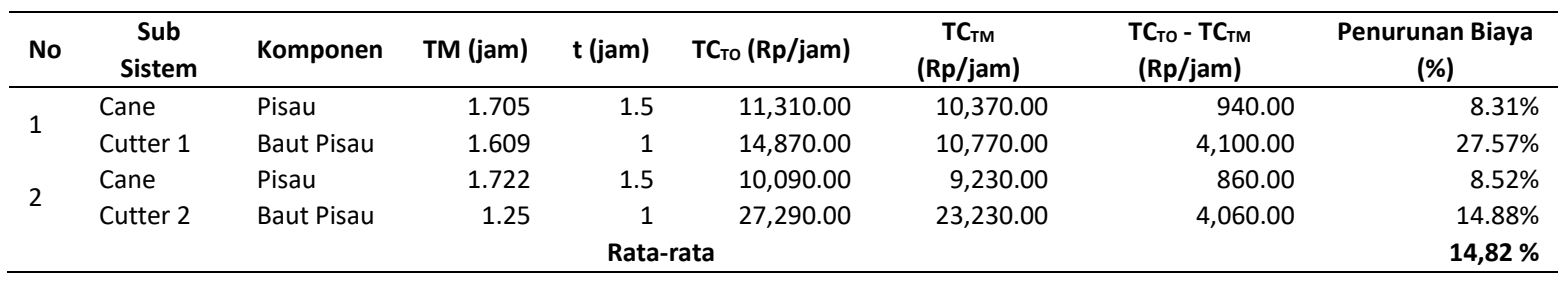

\section{SIMPULAN DAN REKOMENDASI}

Dari hasil pengolahan dan analisa data yang telah dilakukan, maka dapat diambil kesimpulan sebagai berikut :

1. Kebijakan perawatan yang dilakukan untuk mengantisipasi dan mengatasi kegagalan yang terjadi pada komponen mesin Cane Cutter 1 dan 2 adalah proactive task yang meliputi: scheduled restoration task dan scheduled discard task.

2. Rata-rata penurunan biaya perawatan total yang didapatkan dengan mengurangkan "biaya total pada interval perawatan awal' dan 'biaya total pada interval perawatan optimal' adalah 14,82 $\%$.

Adapun saran yang dapat diberikan bagi perusahaan berdasarkan hasil penelitian adalah :

1. Diperlukan penyusunan standar operasi perawatan untuk masing-masing komponen mesin, berdasarkan jenis kegiatan perawatan yang dibutuhkan masing-masing komponen.

2. Diperlukan pencatatan secara berkala pada setiap kegiatan 
perawatan yang dilakukan, baik schedule on condition task, schedule restoration task dan schedule discard task. Hal ini sangat penting untuk mengantisipasi terjadinya kegagalan potensial.

3. Untuk efektifitas kegiatan perawatan, sebaiknya kegiatan perawatan schedule on condition

\section{DAFTAR PUSTAKA}

Hoyland, Arnjlot, and Rausand, Marvin, 1994, System Reliability Theory Models and Stastitical Methods, John Wiley \& Sons Inc., New York.

Iriani, Y., Rahmadi, E.S., (2011), Usulan Waktu Perawatan Berdasarkan Keandalan Suku Cadang Kritis Bus di Perum Damri Bandung, 6th National Industrial Engineering Conference, Universitas Widyatama, Surabaya, hal 171-178.

Moubray, John, 1997, Reliability Centered Maintenance, Second edition, Industrial press inc., New York.

Nordstrom, Jakob, 2007, RCM-based maintenance plans for different operational conditions, Lulea University of Technology.

Pakpahan, Agus, dkk., 2002, Program Akselerasi Peningkatan Produktivitas Gula Nasional, Sekretariat Dewan Gula task dilakukan oleh operator yang bertugas di area peralatan, agar informasi potensi terjadinya kegagalan dapat segera diketahui. Sedangkan untuk kegiatan schedule restoration task dan schedule discard task dapat dilakukan oleh bagian mekanik.
Nasional, Dirjen Bina Produksi Perkebunan, Departemen Pertanian, Jakarta.

Pranoto, J., Matondang, N., dan Siregar, Ikhsan, 2013, Implementasi Studi Preventive Maintenance Fasilitas Produksi Dengan Metode Reliability Centered Maintenance Pada PT. XYZ, .e-Jurnal Teknik Industri FT USU, Vol 1, No 3, hal 18-24.

Rinne, H., 2009, The Weibull Distribution A Handbook, Chapman \& Hall/CRC.

Silva, Carlos Manuel I, 2008, Proactive Reliability Maintenance: a case study conserning maintenance service cost, Journal of Quality in Maintenance Engineering, Vol 14, No 4, pp 343-355.

Soesetyo, I., dan Bendatu, L.Y., 2014, Penjadwalan Predictive Maintenance dan Biaya Perawatan Mesin Pellet di PT Charoen Pokphand IndonesiaSepanjang, Jurnal Titra, Vol 2, No 2 , hal 147-154. 